\title{
What is what? From a palliative care approach to specialized palliative care in heart failure management
}

Tiny Jaarsma, Loreena Hill and Anna Strömberg

The self-archived postprint version of this journal article is available at Linköping University Institutional Repository (DiVA):

http://urn.kb.se/resolve?urn=urn:nbn:se:liu:diva-165.514

N.B.: When citing this work, cite the original publication.

Jaarsma, T., Hill, L., Strömberg, A., (2020), What is what? From a palliative care approach to specialized palliative care in heart failure management, European Journal of Heart Failure. https://doi.org/10.1002/ejhf.1823

Original publication available at:

https://doi.org/10.1002/ejhf.1823

Copyright: Wiley (12 months)

http://eu.wiley.com/WileyCDA/ 
Editorial:

What is what? From a palliative care approach to specialized palliative care in heart failure management

Tiny Jaarsma ${ }^{1,2}$ Loreena Hill ${ }^{3}$, Anna Strömberg ${ }^{1,4}$

1. Department of Health, Medicine and Health Sciences, Linköping University, Linköping, Sweden

2. Julius Center, University Medical Center Utrecht, the Netherlands

3. School of Nursing and Midwifery, Queen's University, Belfast, Northern Ireland.

4. Department of Cardiology, Linköping University Hospital, Linköping University, Linköping. Sweden 
Life for every patient with chronic heart failure is unique. However, unpredictability during the illness trajectory with periods of symptom instability is common leading to feelings of uncertainty both for the patients, the family and the care team. Optimal symptom control and a focus on quality of life has been advocated as main treatment objectives in the HF guidelines. ${ }^{1}$ The development of evidenced-based HF pharmaceutical therapies, devices and surgical management have been impressive during recent decades ${ }^{1,2}$ leading to prolonged survival and improved quality of life for patients with HF. At the same time, it is recognized that a substantial number of patients with HF suffer from distressful and burdensome symptoms through-out the trajectory, from diagnosis to end of life. ${ }^{3,4}$

One strategy to optimally manage symptoms and improve quality of life in HF patients it to adopt a palliative care approach. This approach aims at improving quality of life for patients and families through the prevention and relief of suffering. ${ }^{5}$ Its foci are early expert assessment and management of symptoms, evaluation and support of family members/informal caregivers and an interdisciplinary coordination and planning of ongoing future care. Palliative care in HF has been addressed in numerous Heart Failure Association (HFA) of the European Society of Cardiology conferences, workshops and publications that provide supportive evidence for a greater understanding of the need for palliative care and its integration into daily HF management.

In this issue of the European Journal of Heart Failure Sahlollbey and colleagues present their systematic literature review aggregating results from interdisciplinary palliative care interventions, which they defined as interventions utilizing multiple types of health care providers that targeted multiple domains of palliative care. They conclude that palliative care interventions substantially reduce hospitalizations and may also have positive effects on quality of life and symptom burden. ${ }^{6}$ The finding is to a large extent from the patient perspective disappointing since the symptom relief and physical, mental, psychosocial and existential well-being is the main goal of palliative care. The interventions included in their review were very diverse in content, intensity and team member involved, as shown in their supplementary table. Not only was the content different, also the terminology used to describe palliative care interventions was inconclusive. This diffuse and often confusing use of terminology is evident throughout recent publications that discuss palliative care for patients with $\mathrm{HF}^{4}$

Furthermore, to add to the unclarity of the field other terms such as generalist, or 'primary' palliative care and 'specialist palliative care, palliative care specialists, palliative care teams, 
palliative care consultations, palliative care services, are used without generally accepted definitions. One might wonder 'what's in a name' and why worry about this.

We believe that this diffuse use of terms can lead to misunderstandings amongst the professionals providing care to heart failure patients, as well as among patients and their family caregivers. Unclear use of terms might to some extent explain the limited uptake of the palliative care approach in heart failure management. ${ }^{7,8}$ Talking to colleague health care professionals, one often is confronted with the opinion that palliative care is only for patients who are imminently dying, with many reluctant to use the term 'palliative care' and often feel uncomfortable initiating difficult conversations early in the course of the disease. ${ }^{9}$ This is particularly apparent in the those patients who receive an implantable cardioverter defibrillator. Often the subject of deactivation is introduced to the patient and family members "too little, too late". ${ }^{10}$ Many health care professionals rationalise their actions from the belief that it is in their patients " best interests", as patients will become anxious if the term palliative care is used or might feel deserted and left without hope. ${ }^{8}$ Others, are of the opinion that palliative care is equivalent to terminal or hospice care, when there is an agreement that curative treatment is futile.

In a position statement from the Heart Failure Association of $2009^{11}$ it was stated that palliative care should be integrated as part of a team approach to comprehensive HF care and should not be reserved for those who are expected to die within days or weeks. Following up on that paper, the HFA will soon publish a new position statement on the integration of a palliative approach into heart failure care. That statement will provide clinical guidance on integrating palliative and HF care and advocate the introduction of a palliative care approach for all heart failure patients. This entails that health care professionals focus on relief of physical, psychological, social and/or existential burdens and improving patients' quality of life and spiritual well-being. There undoubtably might be patients, particularly those close to the end of life that need specialist palliative care involvement as proposed in the latest ESC HF clinical guidelines ${ }^{1}$. However, all HF specialists should be familiar with and be equipped to provide a palliative care approach to their patients with HF.

1. Ponikowski P, Voors AA, Anker SD, et al. 2016 ESC Guidelines for the diagnosis and treatment of acute and chronic heart failure: The Task Force for the diagnosis and treatment of acute and chronic heart failure of the European Society of Cardiology (ESC). Developed with the 
special contribution of the Heart Failure Association (HFA) of the ESC. Eur J Heart Fail. 2016;18(8):891-975.

2. Seferovic PM, Ponikowski P, Anker SD, et al. Clinical practice update on heart failure 2019: pharmacotherapy, procedures, devices and patient management. An expert consensus meeting report of The Heart Failure Association of the European Society of Cardiology. Eur J Heart Fail. 2019.

3. Baik D, Reading M, Jia H, Grossman LV, Masterson Creber R. Measuring health status and symptom burden using a web-based $\mathrm{mHealth}$ application in patients with heart failure. Eur J Cardiovasc Nurs. 2019;18(4):325-331.

4. Campbell RT, Petrie MC, Jackson CE, et al. Which patients with heart failure should receive specialist palliative care? Eur J Heart Fail. 2018;20(9):1338-1347.

5. https://www.who.int/reproductivehealth/self-care-interventions/definitions/en/.

6. SahlollbeyN, Seng Lee CK, Shirin A, Joseph P. The impact of palliative care on clinical and patient cantered outcomes in patients with advanced heart failure: a systematic review of randomized controlled trial Eur J Heart Fail (this issue).

7. Hjelmfors L, van der Wal MH, Friedrichsen MJ, Martensson J, Stromberg A, Jaarsma T. Patient-Nurse Communication about Prognosis and End-of-Life Care. J Palliat Med. 2015;18(10):865-871.

8. Jaarsma T, van der Wal M, Hjelmfors L, Stromberg A. Talking about palliative care in heart failure. Eur J Heart Fail. 2018;20(9):1348-1349.

9. Janssen DJ, Boyne J, Currow DC, Schols JM, Johnson MJ, La Rocca HB. Timely recognition of palliative care needs of patients with advanced chronic heart failure: a pilot study of a Dutch translation of the Needs Assessment Tool: Progressive Disease - Heart Failure (NAT:PD-HF). Eur J Cardiovasc Nurs. 2019;18(5):375-388.

10. Hill LM, Mcllfatrick S, Taylor B, Dixon L, Fitzsimons D. Implantable cardioverter defibrillator (ICD) functionality: patient and family information for advanced decision-making. BMJ supportive \& palliative care. 2019.

11. Jaarsma T, Beattie JM, Ryder M, et al. Palliative care in heart failure: a position statement from the palliative care workshop of the Heart Failure Association of the European Society of Cardiology. Eur J Heart Fail. 2009;11(5):433-443. 